NASA/TM-2003-212614

\title{
Advanced Electrical Materials and Component Development
}

Gene E. Schwarze

Glenn Research Center, Cleveland, Ohio 
Since its founding, NASA has been dedicated to the advancement of aeronautics and space science. The NASA Scientific and Technical Information (STI) Program Office plays a key part in helping NASA maintain this important role.

The NASA STI Program Office is operated by Langley Research Center, the Lead Center for NASA's scientific and technical information. The NASA STI Program Office provides access to the NASA STI Database, the largest collection of aeronautical and space science STI in the world. The Program Office is also NASA's institutional mechanism for disseminating the results of its research and development activities. These results are published by NASA in the NASA STI Report Series, which includes the following report types:

- $\quad$ TECHNICAL PUBLICATION. Reports of completed research or a major significant phase of research that present the results of NASA programs and include extensive data or theoretical analysis. Includes compilations of significant scientific and technical data and information deemed to be of continuing reference value. NASA's counterpart of peerreviewed formal professional papers but has less stringent limitations on manuscript length and extent of graphic presentations.

- TECHNICAL MEMORANDUM. Scientific and technical findings that are preliminary or of specialized interest, e.g., quick release reports, working papers, and bibliographies that contain minimal annotation. Does not contain extensive analysis.

- CONTRACTOR REPORT. Scientific and technical findings by NASA-sponsored contractors and grantees.
- CONFERENCE PUBLICATION. Collected papers from scientific and technical conferences, symposia, seminars, or other meetings sponsored or cosponsored by NASA.

- SPECIAL PUBLICATION. Scientific, technical, or historical information from NASA programs, projects, and missions, often concerned with subjects having substantial public interest.

- TECHNICAL TRANSLATION. Englishlanguage translations of foreign scientific and technical material pertinent to NASA's mission.

Specialized services that complement the STI Program Office's diverse offerings include creating custom thesauri, building customized databases, organizing and publishing research results ... even providing videos.

For more information about the NASA STI Program Office, see the following:

- Access the NASA STI Program Home Page at http://www.sti.nasa.gov

- E-mail your question via the Internet to help@sti.nasa.gov

- Fax your question to the NASA Access Help Desk at 301-621-0134

- Telephone the NASA Access Help Desk at 301-621-0390

- Write to:

NASA Access Help Desk

NASA Center for AeroSpace Information 7121 Standard Drive

Hanover, MD 21076 
NASA/TM-2003-212614

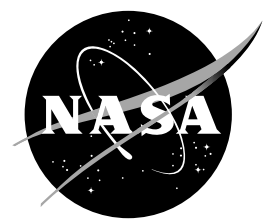

\section{Advanced Electrical Materials and Component Development}

Gene E. Schwarze

Glenn Research Center, Cleveland, Ohio

Prepared for the

First International Energy Conversion Engineering Conference cosponsored by the American Institute of Aeronautics and Astronautics (AIAA), the American Society of Mechanical Engineers (ASME), and the Institute of Electrical and Electronics Engineers (IEEE)

Portsmouth, Virginia, August 17-21, 2003

National Aeronautics and

Space Administration

Glenn Research Center 
Available from

NASA Center for Aerospace Information 7121 Standard Drive

Hanover, MD 21076
National Technical Information Service 5285 Port Royal Road Springfield, VA 22100

Available electronically at http://gltrs.grc.nasa.gov 


\title{
ADVANCED ELECTRICAL MATERIALS AND COMPONENT DEVELOPMENT
}

\author{
Gene E. Schwarze \\ National Aeronautics and Space Administration \\ Glenn Research Center \\ Cleveland, Ohio 44135
}

\begin{abstract}
The primary means to develop advanced electrical components is to develop new and improved materials for magnetic components (transformers, inductors, etc.), capacitors, and semiconductor switches and diodes. This paper will give a description and status of the internal and external research sponsored by NASA Glenn Research Center on soft magnetic materials, dielectric materials and capacitors, and high quality silicon carbide ( $\mathrm{SiC}$ ) atomically smooth substrates. The rationale for and the benefits of developing advanced electrical materials and components for the PMAD subsystem and also for the total power system will be briefly discussed.
\end{abstract}

\section{INTRODUCTION}

All aerospace systems require Power Management and Distribution (PMAD) between the energy/power source and the loads. The PMAD subsystem can be broadly described as the conditioning and control of unregulated power from the energy source and its transmission to a power bus for distribution to the intended loads. One of the major elements of the PMAD subsystem is the DC/DC converter whose function is to transform the source voltage to the required bus voltage, and in many cases, also regulate the bus voltage. The particular topology of the DC/DC converter is dependent on the specific application and accordingly, the DC/DC converter's performance is optimized for a specific requirement such as mass, volume, efficiency, regulation, isolation, or operating environment. For example, increasing the power density by decreasing the mass of the converter usually causes the efficiency to decrease. If the conversion efficiency of the energy source is low, then small decreases in the converter's efficiency can have a significant impact on the end-to-end efficiency of the power system. To compensate for the reduction in system efficiency requires increasing the energy source output to give the required output power. Thus, the mass saved by increasing the power density of the DC/DC converter can be over-shadowed by the increase in the energy source mass due to the reduced efficiency of the DC/DC converter.

All power and control circuits for PMAD require electrical components for switching, rectification, energy storage, voltage/current transformation, filtering, regulation, protection, and isolation. In order to increase the power density, efficiency, operating temperature, and reliability of the PMAD subsystem requires advances in electrical component technology. The primary means to develop advanced electrical components is to develop new and significantly improved materials for capacitors, magnetic components such as transformers and inductors, and semiconductor switches and diodes.

The specific benefits of developing advanced electrical materials and component technology are:

1. Higher operating frequency components give increased power density by reducing the mass and volume of the passive components (transformers, inductors, and filter capacitors). But increasing the frequency does have its downside: switching and diode losses can increase along with loss increases in the magnetic components and capacitors. The result is a decrease in efficiency.

2. Higher operating temperature components give reduced cooling requirements and thus reduce the complexity, size and mass of the thermal transport and radiator subsystem.

3. Higher efficiency components not only give reduced cooling requirements but also reduce the power generation and storage needs for a given output power.

4. Higher radiation resistant components give reduced mass and volume of shielding materials.

5. Higher voltage components give higher power systems and give reduced power transmission cable mass.

From a power system perspective, the benefits of developing advanced electrical components include:

1. Increased payload capability

2. Decreased spacecraft mass/volume/cost

3. Increased design flexibility

4. Increased reliability

Under the Energetics project (which is one of the projects of NASA's Enabling Concepts and Technology Program), the Glenn Research Center has the responsibility for the development of advanced electrical and electronic materials and components. The present focus of this research program is on the following three areas: 
1. New and significantly improved high frequency, high/wide temperature, low loss soft magnetic materials for the development of magnetic components (transformers, inductors, chokes, etc.) with increased power/energy density, electrical efficiency, maximum operating temperature, and temperature range.

2. New and significantly improved dielectric materials for the development of power capacitors with increased volumetric efficiency, electrical efficiency, energy density, maximum operating temperature, and temperature range.

3. Development of high quality $4 \mathrm{H}-$ and $6 \mathrm{H}-$ silicon carbide ( $\mathrm{SiC}$ ) substrates to enable the fabrication of vastly improved high power density, high voltage, high temperature, low loss $\mathrm{SiC}$ switches and diodes.

This paper will give a description and status of these three research areas.

\section{SOFT MAGNETIC MATERIALS}

The magnetic properties of matter are classified as diamagnetic, paramagnetic, ferromagnetic, ferrimagnetic, and antiferromagnetic. Only ferromagnetic and ferrimagnetic materials are of interest to the magnetic component designer. Ferromagnetic materials include iron, cobalt, nickel, their alloys, and some of the rareearth metals. Ferrimagnetic substances are oxides and mixtures of oxides of ferromagnetic metals and these materials are called ferrites. Ferromagnetic and ferrimagnetic materials are of two types; hard and soft. Hard materials require a large magnetizing field for the material to magnetically saturate, and as a result, once magnetized, these materials have a very large intrinsic coercivity and become permanent magnets. Soft magnetic materials require very small magnetizing fields to become magnetically saturated, have a low coercivity, and once the magnetizing field is removed, the flux density essentially goes to zero. NASA Glenn has research programs in both hard and soft magnetic materials but only soft magnetic materials will be discussed in this paper.
The designer of power magnetic components requires specific knowledge about the electrical, magnetic, and thermal properties of the soft magnetic materials used in these components. The desired properties of soft magnetic materials are listed in Table 1. The chances of finding all these desirable properties in any given magnetic material are quite slim so the magnetic component designer must usually perform a trade-off design analysis to select the best material to meet specific design requirements.

A major consideration in power magnetic component design is the core loss. Core loss is the power dissipated in a magnetic material and the classical or conventional approach separates the core loss into hysteresis and eddy current loss components. Hysteresis loss is defined as the energy (heat) expended in a magnetic material as a result of magnetic irreversibility (hysteresis) when the flux density is cyclic. The area of the dc or static B-H hysteresis loop is proportional to the hysteresis loss. The material processing procedure which includes both the type of heat and magnetic anneals determines the shape of the static loop. The eddy current loss is the energy (heat) expended by the circulating (eddy) currents induced through the time variation of the magnetic flux in the core laminations or the convolutions of tape wound cores. The area of the ac or dynamic B-H hysteresis loop gives a qualitative assessment of the core loss. The core loss is a function of several variables which include type of material, lamination or tape thickness, peak operating flux density, operating frequency, operating temperature, type of excitation (voltage or current), and excitation waveform (sine, square, etc.).

Our present soft magnetic materials program is focused on the investigation, characterization, and evaluation of nanocrystalline and nanocomposite magnetic materials. This research includes both in-house and sponsored research and a brief description of this work will now be given.

\begin{tabular}{|c|c|c|}
\hline $\begin{array}{l}\text { High Power/Energy Density } \\
\text { - High Saturation Flux Density, } \\
\mathrm{B}_{\mathrm{s}} \\
\text { - } \\
\text { Flat } \mathrm{B}_{\mathrm{s}} \text { vs. T curve over wide } \\
\text { temperature range }\end{array}$ & $\begin{array}{l}\text { High Temperature } \\
\text { - High Curie Temperature } \\
\text { - High Thermal Conductivity } \\
\text { - } \quad \text { Stable Characteristics under } \\
\text { - Temperature Cycling } \\
\text { - Stable Characteristics at High } \\
\text { - } \quad \text { Predictive Aging Effects }\end{array}$ & $\begin{array}{l}\text { High Efficiency } \\
\text { - Low Coercive Force } \\
\text { - High Permeability at Operating } \\
\text { Flux Density } \\
\text { - } \quad \text { Low Core Loss at Operating } \\
\quad \text { Frequency and Temperature }\end{array}$ \\
\hline
\end{tabular}

Table 1: Desired soft magnetic material properties 
Nanocrystalline magnetic materials are defined in this paper as soft magnetic materials produced by partial crystallization of an amorphous alloy. Amorphous metal or metallic glass is characterized by the absence of any long-range atomic order. Amorphous alloys have no crystalline structure and are therefore isotropic. This isotropy coupled with engineered induced anisotropies allow the amorphous magnetic alloys to exhibit soft magnetic properties with low core loss. The characteristic feature of a nanocrystalline material is a two-phase structure in which fine crystalline grains with dimensions on the order of 10-20 $\mathrm{nm}$ are embedded in an amorphous intergranular phase.

Nanocomposite magnetic materials are defined as soft magnetic materials fabricated by the compaction of insulated, magnetic nanoparticles of dimensions generally less than $50 \mathrm{~nm}$. A ferromagnetic material is made up of small regions of magnetization called domains. The intensity of magnetization, that is, the magnetic moment per unit volume of each domain is equivalent to the saturation or intrinsic magnetization of the bulk material. The magnetic flux density or induction below saturation is determined by the orientation of the magnetic moment of the domains with respect to the applied magnetizing field.

Over the past decade NASA Glenn Research Center has developed in-house a unique measurement system to characterize the core loss and both the static and dynamic B-H hysteresis loops of both inductor and transformer types of soft magnetic materials. Presently the system is capable of making measurements over the temperature range of $-150{ }^{\circ} \mathrm{C}$ to $300{ }^{\circ} \mathrm{C}$, peak flux densities to saturation, frequencies up to $1 \mathrm{MHz}$, and for sine and square wave voltage excitation. An extensive specific core loss (SCL) and static and dynamic B-H hysteresis loop database has been developed and published for polycrystalline alloys [1, 2, 3, 4], amorphous alloys $[1,5]$, nanocrystalline alloy [5], and power ferrites [6].

Table 2 gives a comparison of the SCL for a polycrystalline, amorphous, nanocrystalline, and power ferrite soft magnetic material. The polycrystalline material is a $79 \% \mathrm{Ni}, 17 \% \mathrm{Fe}, 4 \%$ Mo alloy and is known in the trade as Supermalloy. The tape wound toroidal test cores, with two different tape thicknesses, were provided by Magnetics. The amorphous material is a cobalt-based material provided by Vacuumschmelze and designated as $6025^{\circ} \mathrm{F}$. The test specimen was a $23 \mu \mathrm{m}$ thick tape wound toroid. The nanocrystalline material is an iron-based material and was also provided by Vacuumschmelze and designated as $500{ }^{\circ} \mathrm{F}$. This test specimen was also a $23 \mu \mathrm{m}$ thick tape wound toroid. The power ferrite is a solid toroidal core provided by Ceramic Magnetics and designated as MN8CX.

The SCL shown in Table 2 is for three different flux densities at $100 \mathrm{kHz}$ and $25^{\circ} \mathrm{C}$ for sine wave voltage excitation. This table shows that the amorphous material, $6025^{\circ} \mathrm{F}$, has the lowest SCL for all three flux densities followed by the nanocrystalline, $500{ }^{\circ} \mathrm{F}$, and the $6.35 \mu \mathrm{m}$ thick tape polycrystalline material, Supermalloy. The power ferrite has a low SCL at $0.1 \mathrm{~T}$ but then climbs rapidly. Table 2 clearly shows the effect of tape thickness on the SCL for the Supermalloy material. The $25.4 \mu \mathrm{m}$ thick tape Supermalloy material is more than 3 times the SCL for the $6.35 \mu \mathrm{m}$ sample for all flux densities shown. Also, a comparison of the $23 \mu \mathrm{m}$ thick tape amorphous material, $6025^{\circ} \mathrm{F}$, with the $25.4 \mu \mathrm{m}$ thick tape polycrystalline material, Supermalloy, clearly shows that the SCL of the amorphous material is far superior to the polycrystalline material by a factor of more than 4 .

Table 3 shows the effect of frequency on the SCL for the same three materials given in Table 2. For all three frequencies shown, the SCL of the amorphous material is the lowest but now the $6.35 \mu \mathrm{m}$ thick tape polycrystalline material is a close competitor at $300 \mathrm{kHz}$. The nanocrystalline and power ferrite materials have similar SCL and again, the $25.4 \mu \mathrm{m}$ thick tape polycrystalline material has the highest SCL.

From a core loss consideration, the data in Tables 2 and 3 show that the amorphous material, $6025^{\circ} \mathrm{F}$, would most likely be the material of choice by the magnetic

\begin{tabular}{|c|c|c|c|c|c|}
\hline \multicolumn{7}{|c|}{ Specific Core Loss (w/lb) @ $100 \mathrm{kHz}$ and $25^{\circ} \mathrm{C}$} \\
\hline Max Flux Density & $6025 \mathrm{~F}$ & $500 \mathrm{~F}$ & Supermalloy & Supermalloy & MN8CX \\
\hline$(\mathrm{T})$ & $(23 \mu \mathrm{m}$ Tape) & $(23 \mu \mathrm{m}$ Tape) & $(25.4 \mu \mathrm{m}$ Tape) & $(6.35 \mu \mathrm{m}$ Tape $)$ & $($ Solid $)$ \\
\hline 0.1 & 2.9 & 4.0 & 14.6 & 4.1 & 4.8 \\
\hline 0.2 & 11.7 & 15.9 & 54.4 & 17.0 & 33.7 \\
\hline 0.3 & 27.9 & 35.7 & 119 & 37.9 & 98.0 \\
\hline
\end{tabular}

Table 2: Comparison of the specific core loss for a polycrystalline (Supermalloy), amorphous (6025F), nanocrystalline $(500 \mathrm{~F})$ and ferrite $(\mathrm{MN} 8 \mathrm{CX})$ for various flux densities at $100 \mathrm{kHz}$ and $25 \mathrm{C}$ 


\begin{tabular}{|c|c|c|c|c|c|}
\hline \multicolumn{7}{|c|}{ Specific Core Loss $(\mathrm{w} / \mathrm{lb}) @ 0.1 \mathrm{~T}$ and $25^{\circ} \mathrm{C}$ except as noted } \\
\hline Frequency & $\left(50^{\circ} \mathrm{C}\right) 6025^{\circ} \mathrm{F}$ & $\left(50^{\circ} \mathrm{C}\right) 500^{\circ} \mathrm{F}$ & Supermalloy & Supermalloy & MN8CX \\
\hline$(\mathrm{kHz})$ & $(23 \mu \mathrm{m}$ Tape $)$ & $(23 \mu \mathrm{m}$ Tape $)$ & $(25.4 \mu \mathrm{m}$ Tape $)$ & $(6.35 \mu \mathrm{m}$ Tape $)$ & $($ Solid $)$ \\
\hline 100 & 2.9 & 4.0 & 14.6 & 4.1 & 4.8 \\
\hline 200 & 9.9 & 14.8 & No Data & No Data & 14.6 \\
\hline 300 & 19.9 & 30.6 & 94.2 & 22.0 & 32.2 \\
\hline
\end{tabular}

Table 3: Comparison of the specific core loss of a polycrystalline (Supermalloy), amorphous $\left(6025{ }^{\circ} \mathrm{F}\right)$, nanocrystalline $\left(500^{\circ} \mathrm{F}\right)$ and ferrite $(\mathrm{MN} 8 \mathrm{CX})$ magnetic material at various frequencies at $0.1 \mathrm{~T}$ and $25^{\circ} \mathrm{C}$.

components designer if minimum core loss was a design requirement. The data in Tables 2 and 3 also provide a technical basis against which the SCL of new nanocrystalline and nanocomposite magnetic materials can be compared to determine whether they will be competitive with presently available magnetic materials.

Much of the present interest in nanocrystalline and nanocomposite materials has to do with the results published in papers by G. Herzer [7, 8]. These papers give a graphical comparison of several types of magnetic materials by showing the dependence of the coercivity on the material's grain size. The magnetic materials in this comparison include an amorphous Cobased alloy, nanocrystalline Fe-based alloys, and 50-50 $\mathrm{NiFe}$ and $80-20 \mathrm{NiFe}$ polycrystalline alloys. The coercivity versus grain size graph shows that polycrystalline $80-20 \mathrm{NiFe}$ alloys have coercivities in the range of $5 \mathrm{~A} / \mathrm{m}$ to $0.5 \mathrm{~A} / \mathrm{m}$ for grain sizes in the range of 50-100 $\mu \mathrm{m}$, respectively, i.e. the larger grain size has the lower coercivity. The $50-50 \mathrm{NiFe}$ alloys with grain sizes in the range of $10-100 \mu \mathrm{m}$ have coercivities in the range of $100 \mathrm{~A} / \mathrm{m}$ to $5 \mathrm{~A} / \mathrm{m}$. As an Fe-based nanocrystalline alloy approaches a grain size around $100 \mathrm{~nm}$, the coercivity plateaus at around 5000 $\mathrm{A} / \mathrm{m}$ and then proceeds to decrease rapidly to coercivities less than $1 \mathrm{~A} / \mathrm{m}$ for Fe-based nanocrystalline materials with grain sizes on the order of 10-20 nm. The Co-based amorphous alloy with a grain size of less than $1 \mathrm{~nm}$ has a coercivity of about $0.5 \mathrm{~A} / \mathrm{m}$ which is about the same as the polycrystalline $80-20 \mathrm{NiFe}$ alloy with grain size of $100 \mu \mathrm{m}$.

The dc coercivity is a measure of the hysteresis loss so the question arises as to why the nanocrystalline and nanocomposite magnetic alloys are of interest if their coercivities are equal or greater than the $80-20 \mathrm{NiFe}$ alloy coercivities. For nanocrystalline alloys the reason is they contain non-metallic elements such as $\mathrm{Si}$ and $\mathrm{B}$ and these additives greatly increase the resistivity. In the case of nanocomposite magnetic materials, the resistivity should be high because the magnetic nanoparticles are coated with an electrical insulator.
Polycrystalline magnetic alloys have low resistivities and small additions of non-magnetic elements are added to increase their resistivities. For example, the polycrystalline Supermalloy alloy in Tables 2 and 3 is a nominal 80-20 NiFe alloy with Mo added to give Supermalloy a resistivity of 57 microohm $\mathrm{cm}$ [9]. The Fe-based nanocrystalline alloy, $500{ }^{\circ} \mathrm{F}$, in Tables 2 and 3 , has a resistivity of 115 microohm $\mathrm{cm}$ [10], which is a $2 \mathrm{X}$ increase over Supermalloy.

As previously discussed the core loss is the sum of the hysteresis and eddy current loss. Classical theory shows that the eddy current loss is inversely proportional to the resistivity. So by increasing the resistivity, the core loss of a nanocrystalline or nanocomposite magnetic alloy can be much lower than a polycrystalline alloy with dc coercivities about the same as for a nanocrystalline or nanocomposite alloy. Table 2 shows that the SCL of the $25.4 \mu \mathrm{m}$ thick tape polycrystalline alloy, Supermalloy, is more than $3 \mathrm{X}$ the SCL of the $23 \mu \mathrm{m}$ thick tape Fe-based nanocrystalline alloy, $500^{\circ} \mathrm{F}$. However, by reducing the tape thickness of the polycrystalline alloy from $25.4 \mu \mathrm{m}$ to $6.35 \mu \mathrm{m}$, then the SCL of the Fe-based nano-crystalline alloy and polycrystalline alloy become almost equal.

Presently NASA is sponsoring one nanocrystalline and two nanocomposite magnetic materials research investigations. The nanocrystalline research is being conducted in collaboration with the Department of Materials Science and Engineering, Carnegie Mellon University (CMU) under the NASA Graduate Student Research Program (GSRP). This work is part of a PhD thesis project. The nanocomposite research is being conducted under two Phase II Small Business Innovative Research (SBIR) awards.

The objective of the nanocrystalline work with CMU is to develop a high temperature $\left(600{ }^{\circ} \mathrm{C}\right)$ nanocrystalline alloy with high saturation induction and low core loss. Recently, CMU reported on a new class of nanocrystalline magnetic alloys $[11,12]$. These alloys with a composition of ( $\mathrm{Fe}, \mathrm{Co}$ )-M-B-Cu (where $\mathrm{M}=\mathrm{Zr}$ and $\mathrm{Hf}$ ) have been named HITPERM. The HITPERM alloys are synthesized through partial re-crystallization of amorphous precursors. The HITPERM class of 
nanocrystalline magnetic alloys show a large magnetic induction at elevated temperature but the core loss is relatively high compared to other commercial nanocrystalline alloys. The GSRP principal investigator is presently focusing his efforts on investigating HITPERM compositional variants and annealing techniques to reduce the core loss without causing a significant decrease in either the saturation induction or operating temperature.

A nanocomposite magnetic material consists of a core (magnetic metal) - shell (electrical insulator) nanostructure. The main nanocomposite processing steps are: synthesis of magnetic nanoparticles, coating of nanoparticles with electrical insulator, and consolidation or compaction of the insulated nanoparticles (powder) into a solid of near theoretical density to produce bulk materials with different shapes and sizes. Synthesis methods include chemical, sol-gel, plasma arc, and high-energy ball milling.

Coating the magnetic nanoparticle electrically passivates the particle's surface and serves three very important purposes: (1) prevents oxidation since the particles are extremely chemically reactive and pyrophoric at ambient conditions, (2) develops a significant barrier to eddy currents by increasing the nanostructure resistivity, and (3) hinders grain growth or particle agglomeration of the insulated particles during compaction at high temperature.

The consolidation of the nanocomposite powder into a solid is the critical step in developing the soft magnetic properties (i.e. low coercivity and high permeability) in a nanocomposite solid magnetic material. An isolated nanocomposite particle possesses very high anisotropy and demagnetizing effect. An isolated particle has an effective permeability of unity. For a nanocomposite magnetic material to exhibit soft magnetic properties requires that the magnetic moments of neighboring particles be magnetically coupled by what is known as magnetic moment exchange coupling. A critical parameter, the exchange coupling length, is the distance within which the magnetic moments of the neighboring particles can be coupled. If the distance between the neighboring particles is greater than the exchange length, i.e. poor compaction of the powder, then a nanocomposite magnetic solid will result with poor soft magnetic properties.

The consolidation or compaction process used must be capable of making the particle separation distance less than the critical exchange coupling length. Each magnetic alloy has its own critical exchange coupling length. Consolidation methods include sintering, hot press, hot isostatic press, detonation compaction, dynamic magnetic compaction, and electro-discharge compaction. The difficulty involved in any consolidation technique lies in obtaining full densification of the particle assembly without destroying the nanostructure of the particles. To produce nanocrystalline solids with acceptable soft magnetic properties requires that the nanoparticles be exchanged coupled with their neighbors. Thus, any synthesis process used to produce free standing nanoparticles must use a compaction technique in which full densification of the solid occurs and the coated magnetic nanoparticles end up exchange coupled.

It should be noted that a very important advantage of nanocomposite over nanocrystalline magnetic materials is that nanocomposite core fabrication begins with a powder just like ferrites. Nanocrystalline materials start with amorphous precursor thin tapes and remain so after being partially crystallized. Ferrite cores come in many different shapes and sizes and so nanocomposite magnetic materials should likewise be capable of producing various sizes and shapes not achievable with nanocrystalline magnetic tapes. The potential advantage of the nanocomposite over the ferrite is that the nanocomposite has the potential to have higher saturation induction, higher operating temperature, and lower core loss than the power ferrites.

As previously indicated our nanocomposite research is being conducted under two Phase II SBIRs. Each company is using a different synthesis and passivation nanocomposite process and compaction techniques. The present research results obtained by these companies can not be discussed at this time because each company considers their research results to be proprietatry information.

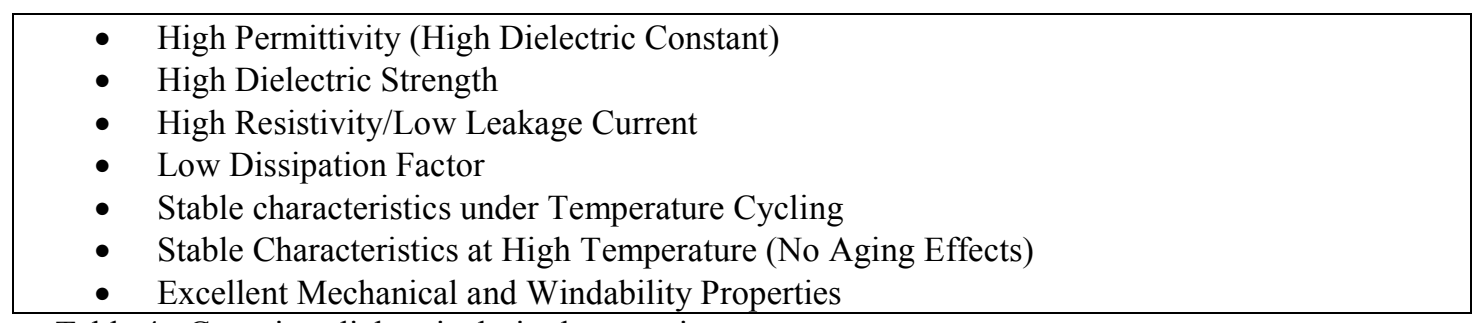

Table 4: Capacitor dielectric desired properties. 


\begin{tabular}{|l|l|l|}
\hline Material & Dielectric Constant & Dielectric Strength (V/mil) \\
\hline Air & 1.0 & 75 \\
Kraft paper (imp.) & 4.0 & 2,000 \\
Polymers & $2.5-3.0$ & $5,000-9,000$ \\
Mica & $5.4-8.7$ & 1,400 \\
Glass & $3.0-4.5$ & 500 \\
Tantalum Pentoxide & 26 & - \\
Aluminum Oxide & 7.0 & 300 \\
Ceramics & $12-400,000$ & $200-350$ \\
\hline
\end{tabular}

Table 5: Dielectric constant and dielectric strength of select dielectric materials

\section{DIELECTRICS AND CAPACITORS}

Capacitors are generally divided into three main groups: electrostatic, electrolytic, and electrochemical. Electrostatic capacitors are of main interest in this discussion. They consist of paper and polymer films, ceramic, and mica. Paper and polymer film capacitors are further broken down into metallized and film-foil construction.

Although a capacitor is simply a set of metal electrodes with a dielectric material stuck in between them, the technology to develop higher performance, high temperature dielectrics is far from simple. Table 4 gives a listing of desired capacitor dielectric properties. Just as for soft magnetic materials, the chance of finding all these desirable properties in any given dielectric material is very low.

A comparison of two of these properties, dielectric constant and dielectric strength (voltage per unit dielectric thickness), is given in Table 5 for several different dielectrics. Polymer film and ceramic capacitors make up much of the commercial electrostatic market. A comparison of these two dielectrics in Table 5 shows that polymer films have relatively low dielectric constants and high dielectric strengths while ceramics have just the opposite, high dielectric constants and low dielectric strengths.

Two figures of merit commonly used in capacitor technology are volumetric efficiency and energy density. The volumetric efficiency is usually used for filter capacitors and the energy density for storage and pulse capacitors.

Capacitance, $\mathrm{C}$, is defined as:

$$
\mathrm{C}=\frac{€ \mathrm{~A}}{\mathrm{t}}=\underline{\epsilon}_{\mathrm{t}} \underline{\epsilon}_{\mathrm{r}} \underline{\mathrm{A}} \quad \text { farad }
$$

where:

$$
\begin{aligned}
& €=€_{\mathrm{r}} €_{\mathrm{o}}=\text { permittivity farad } / \text { meter } \\
& €_{\mathrm{o}}=\text { Free space permittivity } \quad=8.85 \times 10^{-12} \text { farad } / \text { meter } \\
& \epsilon_{\mathrm{r}}=\text { Relative permittivity dimensionless } \\
& \mathrm{A}=\text { Dielectric surface area } \text { meter }^{2} \\
& \mathrm{t}=\text { Dielectric thickness meter }
\end{aligned}
$$

For comparing just the volumetric efficiency of the capacitor dielectric, equation (1) is divided by the dielectric volume, $(\mathrm{Vol})_{\mathrm{d}}$, to give:

$$
\frac{\mathrm{C}}{(\mathrm{Vol})_{\mathrm{d}}}=\underline{€_{\mathrm{o}}} \frac{\epsilon_{\mathrm{r}}}{\mathrm{t}^{2}} \quad \text { farad } / \text { meter }^{3}
$$

where:

$$
(\mathrm{Vol})_{\mathrm{d}}=\text { At } \text { meter }^{3}
$$

Equation (2) shows the dielectric volumetric efficiency can be increased by increasing $€_{\mathrm{r}}$ or decreasing $\mathrm{t}$ and because $t$ is squared, this appears to be the best approach but the limit for decreasing $t$ is the dielectric strength. As the rated capacitor voltage increases, so also must the dielectric thickness so as not to cause voltage breakdown by exceeding the material's dielectric strength.

The volumetric efficiency for commercially packaged capacitors using an electrolytic, polymer film, and ceramic dielectric is given in Table 6 . In this table the volume is that of the packaged capacitor. The table shows for the $100 \mathrm{~V}$ capacitors that the wet tantalum has the highest volumetric efficiency followed by the aluminum electrolytic, then the Z5U Multi-Layer Ceramic Capacitor (MLCC), and finally the metallized polyester film capacitor for the film types. This comparison is really not a fair comparison because when doing a volumetric efficiency comparison, not only should the voltage be the same, but also the capacitance. But finding capacitors which are constructed from different dielectric materials with the same capacitance and voltage rating is practically impossible.

It is of interest to see how capacitors with the same capacitance but different voltage rating compare in volumetric efficiency. In Table 6 two cases are listed. The volumetric efficiency of the $3 \mu \mathrm{f}, 200 \mathrm{~V}$ polyester film-foil capacitor decreases by $45 \%$ compared to the $100 \mathrm{~V}$ capacitor. In the case of the $120 \mu \mathrm{f}$ ceramic X7R capacitor, the volumetric efficiency of the 
$200 \mathrm{~V}$ capacitor decreases by $33 \%$ compared to the $100 \mathrm{~V}$ capacitor. In both cases the volumetric efficiency decreased with voltage for the same capacitance but the ceramic capacitor dielectric had a smaller decrease than the film capacitor dielectric. The reason for this decrease in volumetric efficiency can be seen from Equation (2). The higher voltage rated capacitors need the dielectric thickness to be increased to prevent voltage breakdown and as Equation (2) shows, an increase in dielectric thickness will cause a decrease in the volumetric efficiency of the dielectric with a resultant increase in the volume of the packaged capacitor.

The other figure of merit, energy density, is defined as the energy per unit volume. The energy, E, stored in a capacitor is given by:

$$
\mathrm{E}=\frac{1}{2} \mathrm{CV}^{2} \quad \text { joule }
$$

where:

$$
\mathrm{V}=\text { Rated Voltage volts }
$$

Energy density of a capacitor is defined as the energy per unit volume or mass, and just as in the definition of volumetric efficiency, energy density includes not only the dielectric but also the electrodes and package. For comparing just the energy density of the capacitor's dielectric, equation (3) is divided on both sides by $(\mathrm{Vol})_{\mathrm{d}}$ to give:

$$
\frac{\underline{\mathrm{E}}}{(\mathrm{Vol})_{\mathrm{d}}}=\underline{\epsilon_{\mathrm{o}}} \underset{2}{2} \frac{\epsilon_{\mathrm{r}}}{(\mathrm{Col})_{\mathrm{d}}} \frac{\mathrm{CV}^{2}}{2} \underline{\epsilon}_{\mathrm{t}^{2}} \underline{\epsilon}_{\underline{\mathrm{r}}} \mathrm{V}^{2} \quad \text { joule } / \text { meter }^{3}
$$

Equation (4) shows that the energy density is proportional to the product of the volumetric efficiency and voltage squared. A capacitor with high volumetric efficiency capable of operating at high voltage will have high energy density. Equation (4) clearly shows that the means to a high energy density capacitor is a high operating voltage and trade-off here is dielectric strength versus operating voltage to achieve the minimum dielectric thickness.
NASA Glenn Research Center is presently sponsoring capacitor research in ceramic and diamond-like carbon (DLC) dielectrics. The ceramic dielectric research is investigating nanomaterials and high temperature capacitor dielectrics. Developing new materials to increase the volumetric efficiency and energy density is a challenge, but perhaps a bigger challenge is the development of high temperature $\left(>200{ }^{\circ} \mathrm{C}\right)$ capacitors capable of long-life and high reliability beyond the temperatures $\left(85-125{ }^{\circ} \mathrm{C}\right)$ of most commercial capacitors. The capacitor is presently considered the weakest link in the development of high temperature PMAD subsystems.

Under a Phase II SBIR contract, ceramic dielectric nanomaterials are being investigated. The initial results in Phase I showed that the nanomaterial chip specimens exhibited, compared to coarse grain ceramic capacitors, an insulation resistance increase of more than $10 \mathrm{X}$ at $25^{\circ} \mathrm{C}$ and about $5 \mathrm{X}$ at $200{ }^{\circ} \mathrm{C}$, and an increase in dielectric strength of up to $2 \mathrm{X}$. The emphasis of the Phase II work is on high temperature $\left(>200{ }^{\circ} \mathrm{C}\right)$ MLCCs rather than ceramic nanomaterials. The present research being performed under Phase II is considered proprietary data by the contractor so no additional details can be discussed at this time. Under a grant to the Materials Research Institute, Pennsylvania State University (PSU), high temperature (200-300 $\left.{ }^{\circ} \mathrm{C}\right)$ ceramic dielectrics are also being investigated. This research effort is exploring, developing, and characterizing a range of compositions in the $\mathrm{Pb}\left(\mathrm{Zr}_{\mathrm{x}^{-}}\right.$ $\left.\mathrm{Ti}_{1-\mathrm{x}}\right) \mathrm{O}_{3}$ system, commonly referred to as PLTZ. This ceramic composition has significantly higher Curie temperatures then the $\mathrm{BaTiO}_{3}$ system and this will allow for fabricating high temperature MLCCs. The $\mathrm{BaTiO}_{3}$ system is the ceramic composition used in most commercial MLCCs. A major emphasis of this work is to investigate long-term failure mechanisms associated with electrochemical, electromigration, and electromechanical effects. This failure mechanism investigation will be mostly done by using the HighlyAccelerated-Lifetime-Test (HALT) in which the

\begin{tabular}{|l|c|c|l|}
\hline Type & Capacitance $(\boldsymbol{\mu f})$ & Voltage $(\mathbf{V})$ & $\mathbf{C} / \mathbf{V o l}\left(\boldsymbol{\mu f} / \mathbf{c m}^{\mathbf{3}}\right)$ \\
\hline Wet Tantalum & 120 & 100 & 62 \\
Solid Tantalum & 10 & 100 & 8.9 \\
Al Electrolytic & 18,000 & 100 & 48 \\
\hline Polyester Film-Foil & 3 & 100 & 0.22 \\
Polyester Film-Foil & 10 & 200 & 0.12 \\
Metallized Polyester & 10 & 100 & 1.59 \\
\hline COG/NPO & 12 & 100 & 0.3 \\
X7R & 120 & 100 & 4.5 \\
X7R & 120 & 200 & 3.0 \\
Z5U & 720 & 100 & 18 \\
\hline
\end{tabular}

Table 6: Capacitor volumetric efficiency for different types of dielectrics 
leakage currents will be monitored at elevated temperatures and high electric fields. The grant's principal investigator is in the process of publishing his research results.

Diamond-like-carbon (DLC) is an amorphous film and possesses the unique properties of high dielectric strength, high resistivity, high decomposition temperature, low loss, chemical inertness, and good thermal conductivity. These very desirable properties make DLC films of high interest for capacitor applications. DLC also offers very smooth, flexible films which can be deposited directly on aluminum foils or aluminum coated polymer film with excellent adhesion and with very thin coating thickness.

NASA Glenn Research Center is in partnership with the Air Force Research laboratory (AFRL) at Wright Patterson Air Force Base (WPAFB) to develop a prototype manufacturing technology to produce high quality capacitor grade DLC film on aluminum for fabricating high voltage, high temperature, high volumetric efficient, and high energy density capacitors.

The production of DLC coated aluminum foils at WPAFB uses a dual hydrocarbon ion beam deposition system. The gases normally used are methane and hydrogen. The aluminum foil coating system, i.e. the web-handling system, utilizes a closed loop servo-drive system to control foil tension and speed. The system is capable of operating in both forward and reverse directions. Through tension and speed control, a long length of DLC film deposited on both sides of the aluminum foil can be produced.

By depositing the DLC film on both sides of the aluminum foil, the undesirable effect of pin holes is greatly reduced. Pin holes create an air gap between adjacent layers of the capacitor's electrodes. The dielectric constant of air is unity which is less than the dielectric film, so the greatest voltage stress is across the air gap and as a result, voltage break down occurs with subsequent capacitor failure.

Recent experimental results [13] show that present typical DCL films being fabricated contain about 60 atomic \% carbon and 40 atomic \% hydrogen. The dielectric constant is about 3.5, breakdown voltage strength is greater than $650 \mathrm{~V} / \mu \mathrm{m}(16.5 \mathrm{kV} / \mathrm{mil})$ with a dc resistivity greater than $10^{14} \mathrm{ohm} \mathrm{cm}$. A wound DLC prototype capacitor was recently fabricated and its capacitance as a function of frequency over the temperature range of $-50{ }^{\circ} \mathrm{C}$ to $250{ }^{\circ} \mathrm{C}$ was characterized. The capacitance values from $-50{ }^{\circ} \mathrm{C}$ to $250{ }^{\circ} \mathrm{C}$ were found to be constant from about $100 \mathrm{~Hz}$ to about $500 \mathrm{kHz}$ with the capacitance decreasing at the upper frequency and increasing at the lower frequency. Work continues on the development of higher quality capacitor grade DLC films, longer lengths of wrinklefree films, and fabrication of prototype capacitors for characterization of capacitance as a function of frequency, temperature, and dissipation factor. Prototype DLC capacitors are also to be tested in $\mathrm{DC} / \mathrm{DC}$ converters.

\section{WIDE BANDGAP SEMICONDUCTOR MATERIALS}

PMAD subsystems that simultaneously require high temperature, high voltage, and high power operation will require the use of wide bandgap semiconductor switches (MOSFETs, IGBTs, BJTs, and Thyristors, etc) and diodes (pn junction, and Schottky). Semiconductor devices that can function at temperatures beyond 150$175^{\circ} \mathrm{C}$ without external cooling could greatly benefit not only future aerospace power systems but also the automotive and energy production industries. Present high power and high voltage semiconductor devices use silicon (Si)-based technology. The high density of intrinsic carriers of $\mathrm{Si}$ at elevated temperatures make high power, high voltage $\mathrm{Si}$ devices not useable above $150-175^{\circ} \mathrm{C}$.

Silicon carbide (SiC)-based and III-nitride-based devices (primarily GaN) are the most developed wide bandgap semiconductors but many issues require resolution. $\mathrm{SiC}$ is the most mature wide bandgap material, in terms of the development of high temperature, high voltage power devices. The Advanced Electrical Component Technology program sponsors both $\mathrm{SiC}$ and $\mathrm{GaN}$ research but the primary emphasis is on the development of $\mathrm{SiC}$ power devices. Accordingly, the rest of this discussion will be on the development of higher quality $\mathrm{SiC}$ substrates for fabricating reliable high power, high voltage, and high temperature devices.

Some of the major advantages of $\mathrm{SiC}$ compared to $\mathrm{Si}$ are the following:

1. SiC has a critical electric field of about $10 \mathrm{X}$ or more (depending on polytype) compared to $\mathrm{Si}$. This advantage results in higher device breakdown voltage capability and thus drift regions and voltage hold-off layers can be thinner.

2. SiC device die are thinner because of the above advantage of high breakdown voltage. Thinner die mean lower on-state resistance.

3. SiC can have higher doping, again because of the higher breakdown voltage capability. This situation also leads to lower on-state resistance and 
lower conduction losses and, therefore, higher efficiency.

4. $\mathrm{SiC}$ has a thermal conductivity almost $2 \mathrm{X}$ greater than $\mathrm{Si}$. This gives a lower junction-to-case thermal resistance because heat is more easily conducted from the device junction(s) with a resultant decrease in temperature rise.

5. $\mathrm{SiC}$ can operate at high temperature because of its wider bandgap and thus reduces or possibly eliminates the need for external cooling.

The present consensus seems to be that $\mathrm{SiC}$ devices will be used in a large number of applications once they become commercially available. Presently the only commercially available $\mathrm{SiC}$ devices are Schottky diodes and Cree [14], Infineon Technologies AG [15], Microsemi [16], and Solid State Devices [17] have a product line for these devices. The introduction of other $\mathrm{SiC}$ devices such as power switches into the commercial market will require the resolution of many technical issues including material quality, contacts, $\mathrm{SiC} /$ oxide interface, passivation, and packaging.

In $\mathrm{SiC}$ materials the presence of device-killing defects such as micropipes as well as densely populated screw dislocations is a critical issue requiring resolution. Power devices require large area substrates and until the material's issue is solved, present $\mathrm{SiC}$ technology will be limited to low current devices. Another challenge is developing durable and reliable metal-semiconductor contacts and interconnects because poor quality contacts are a primary limiting factor for high temperature operation of power devices. The present quality of the $\mathrm{SiC} /$ oxide interface is a fundamental problem because it prevents the development of gated devices such as MOSFETs and IGBTs. Quality passivants are also needed to prevent surface leakage and high voltage breakdown at junction interfaces. Another hurdle to surmount is high temperature packages capable of reliable operation at temperatures $>200{ }^{\circ} \mathrm{C}$. Major technical challenges to realizing high temperature packages include chemical, mechanical, and electrical stability of both packaging materials as well as the interfaces between these materials. For a more detailed discussion of these technical issues the reader is referred to references $[18,19]$.

The development of $\mathrm{SiC}$ crystal growth and device fabrication technology is presently based on the hexagonal $4 \mathrm{H}$-and $6 \mathrm{H}-\mathrm{SiC}$ polytypes. Mass produced wafers of these polytypes with reasonable size and quality have been commercially available for over a decade. Improving the quality of $4 \mathrm{H}$-and $6 \mathrm{H}-\mathrm{SiC}$ wafers is an on-going effort and various approaches are being investigated. The Advanced Electrical Components Technology Program is sponsoring research with the Sensors and Electronics Technology Branch, NASA Glenn Research Center, to investigate a new approach to develop higher quality $4 \mathrm{H}-$ and $6 \mathrm{H}-$ $\mathrm{SiC}$ substrates and also to grow $3 \mathrm{C}-\mathrm{SiC}$ films on these substrates.

The NASA Glenn research team has demonstrated the growth of step-free surfaces on device-size $\mathrm{SiC}$ mesas [20]. This new growth process to produce atomically smooth or flat surfaces is called "step-free surface heteroepitaxy". On commercial $4 \mathrm{H}-\mathrm{SiC}$ wafers, step free mesas with dimensions up to $200 \mu \mathrm{m}$ square have been demonstrated while on a $6 \mathrm{H}-\mathrm{SiC}$ wafer, step free mesas with dimensions up to $50 \mu \mathrm{m}$ have been produced [20]. This new homoeptaxial growth process is performed on the mesas under conditions that promote step-flow growth and at the same time suppresses 2D nucleation on the mesa top. A description of this process is given in reference 20 .

The density of screw dislocations in the $\mathrm{SiC}$ wafers is a limiting factor in scaling up the size and yield of the step free mesas. The mesas containing screw dislocations could not be made step free because of the continual spiral of new growth steps emanating from the screw dislocations during the homoepitaxial growth process [21]. To overcome this deficiency in the growth process, the research team has developed a $\mathrm{SiC}$ homeopitaxial lateral "web growth" process [21]. Experimental analysis of the webbed regions formed over a micropipe and closed-core screw dislocations show that c-axis propagation of these defects is terminated by the "web growth" process [22]. The present "web growth" process is not considered to be optimized but webbed surfaces as large as $4 \times 10^{-3} \mathrm{~cm}^{2}$ have been grown. This area represents more than $4 \mathrm{X}$ the pre-growth mesa area [22].

The growth of defect free $3 \mathrm{C}-\mathrm{SiC}$ on $4 \mathrm{H}$-and $6 \mathrm{H}-\mathrm{SiC}$ mesas has been demonstrated using the new step free surface heteroepitaxial growth process [23]. The ability to produce high quality $3 \mathrm{C}-\mathrm{SiC}$ heteroepitaxial films free from extended crystal defects could enable the development of $\mathrm{SiC}$ switches and diodes with significantly improved performance ratings in voltage, current, temperature, and on-state losses.

\section{CONCLUSION}

Advanced aerospace systems will require the availability of high performance electrical components in the PMAD subsystem. The primary means to develop these advanced, high performance components is to develop new and significantly improved materials for magnetic components, capacitors, and semiconductor switches and diodes. The emphasis of 
NASA Glenn Research Center's Advanced Electrical Component Technology program is to develop high performance components capable of higher frequency and higher temperature operation, higher efficiency, and higher radiation tolerance. The purpose of the paper is to give (1) the motivation for developing advanced electrical materials and components by delineating the benefits for both the PMAD subsystem and the power system, (2) the rationale for selecting the magnetic, dielectric, and semiconductor materials being investigated and developed and the prior theoretical or experimental research to justify the selection, and (3) the status of the work being done internally, through partnerships, and contract and grant sponsorship.

\section{REFERENCES}

1. Weiserman, W. R., G. E. Schwarze, J. M. Niedra, "Comparison of High Frequency, High Temperature Core Loss and B-H Loop Characteristics of an $80 \mathrm{Ni}$-Fe Crystalline Alloy and two Iron-Based Amorphous Alloys", Eighth Symposium on Space Nuclear Power Systems Proceedings, Part Three, Albuquerque, N.M., January 6-10, 1991.

2. Weiserman, W. R., G. E. Schwarze, J. M. Niedra, "Comparison of High Temperature, High Frequency Core Loss and Dynamic B-H Loops of Two $50 \mathrm{Ni-Fe}$ Crystalline Alloys and an IronBased Amorphous Alloy", $26^{\text {th }}$ Intersociety Energy Conversion Engineering Conference Proceedings, Boston, MA, August 4-9, 1991.

3. Weiserman, W. R., G. E. Schwarze, J. M. Niedra, "Comparison of High Temperature, High Frequency Core Loss and Dynamic B-H Loops of a 2V-49Fe49Co and a Grain Oriented 3Si-Fe Alloy", $27^{\text {th }}$ Intersociety Energy Conversion Engineering Conference, San Diego, CA, August 3-7, 1992.

4. Schwarze, G. E., W. R. Weiserman, J. M. Niedra, "Effects of Temperature, Frequency, Flux Density, and Excitation Waveform on the Core Loss and Dynamic B-H Loops of Supermalloy", 30 $0^{\text {th }}$ Intersociety Energy Conversion Engineering Conference, Orlando, FL, August 4, 1995.

5. Niedra, J. M., G. E. Schwarze, "Wide Temperature Core Loss Characteristics of Transverse Magnetically Annealed Amorphous Tapes for High Frequency Aerospace Magnetics", $34^{\text {th }}$ Intersociety Energy Conversion Engineering Conference, Vancouver, British Columbia, Canada, August 1-5, 1999.

6. Niedra, J. M., "Comparative Wide Temperature Core Loss Characteristics of Two Candidate Ferrites for the NASA/TRW 1500W PEBB Converter", NASA/CR1999-209302. August 1999.
7. Herzer, G., "Grain Size Dependence of Coercivity and Permeability in Nanocrystalline Ferromagnet, "IEEE Transactions on Magnetics, Vol. 26, No. 5, September 1990, pp. 1397-1402.

8. Herzer, Giseller, "Nanocrystalline Soft Magnetic Materials," Journal of Magnetism and Magnetic Materials". 112 (1992) pp. 258-262.

9. "Magnetics, Tape Wound Cores Design Manual, TWC-500, 1998.

10. "Vaccumschmelze, Nanocrystalline Vitroperm 500F, http://www.vaccumschmelze.de.index1.htm

11. Willard, M. A., et al, "Structure and Magnetic Properties of $\left(\mathrm{Fe}_{0.5} \mathrm{Co}_{0.5}\right)_{88} \mathrm{Zr}_{7} \mathrm{~B}_{4} \mathrm{Cu}_{1}$ Nanocrystalline Alloys", Journal of Applied Physics, Volume 84, Number 12, December 15, 1998, pp. 6773-6777.

12. Willard, M. A., et al, "Magnetic Properties of HITPERM (Fe, Co) ${ }_{88} \mathrm{Zr}_{7} \mathrm{~B}_{4} \mathrm{Cu}_{1}$ Magnets", Journal of Applied Physics, Volume 85, Number 8, 15 April, 1999, pp. 4421-4423.

13. Wu, Richard L. C., et al, Thin Film Diamond-LikeCarbon Dielectrics, International Power Modulator Conference, Hollywood, CA., June 30-July 3, 2002.

14. Cree,http://www.cree.com/products/power/ index.htm

15. Infineon Technologies AG-Products-Silicon Carbide Schottky Diode, http://www.infineon.com

16. Microsemi Products >Power Conditioning $>$ Silicon Carbide (SiC) Schottky, http://www.microsemi.com

17. Solid State Devices, http://www.ssdi-power.com

18. Neudeck, P.G., R. S. Okojie,L. Chen, High Temperature Electronics-A Role for Wide Bandgap Semiconductors?, Proceedings of the IEEE, Vol. 90, No. 6, pp. 1065-1076, June 2002.

19. Powell, J. A., L. B. Rowland, SiC materials-Progress, status, and potential road blocks, Proceedings of the IEEE, Vol. 90, pp. 942-955, June 2002.

20. Powell, J. Anthony, et al, Growth of step-free surfaces on device-size (0001) mesas, Applied Physics Letters, Volume 77, Number 10, pp. 14491451, 4 September, 2000.

21. Neudeck, Phillip G., et al, Growth of Defect-Free $3 \mathrm{C}-\mathrm{SiC}$ on $4 \mathrm{H}-$ and $6 \mathrm{H}-\mathrm{SiC}$ Mesas Using Step-Free Surface Heteroepitaxy, Materials Science Forum, Vols. 389-393 (2002) pp. 311-314.

22. Neudeck, Phillip G., et al, Enlargement of step-free $\mathrm{SiC}$ surfaces by homoepitaxial web growth of thin SiC centilevers; Journal of Applied Physics, Volume 92, Number 5, 1 September, 2002, pp. 2391-2400.

23. Neudeck, Phillip G., et al, Homoepitaxial "Web Growth" of $\mathrm{SiC}$ to Terminate C-Axis Screw Dislocations and Enlarge Step-Free Surfaces, Materials Science Forum, Vols. pp. 389-393 (2002). 


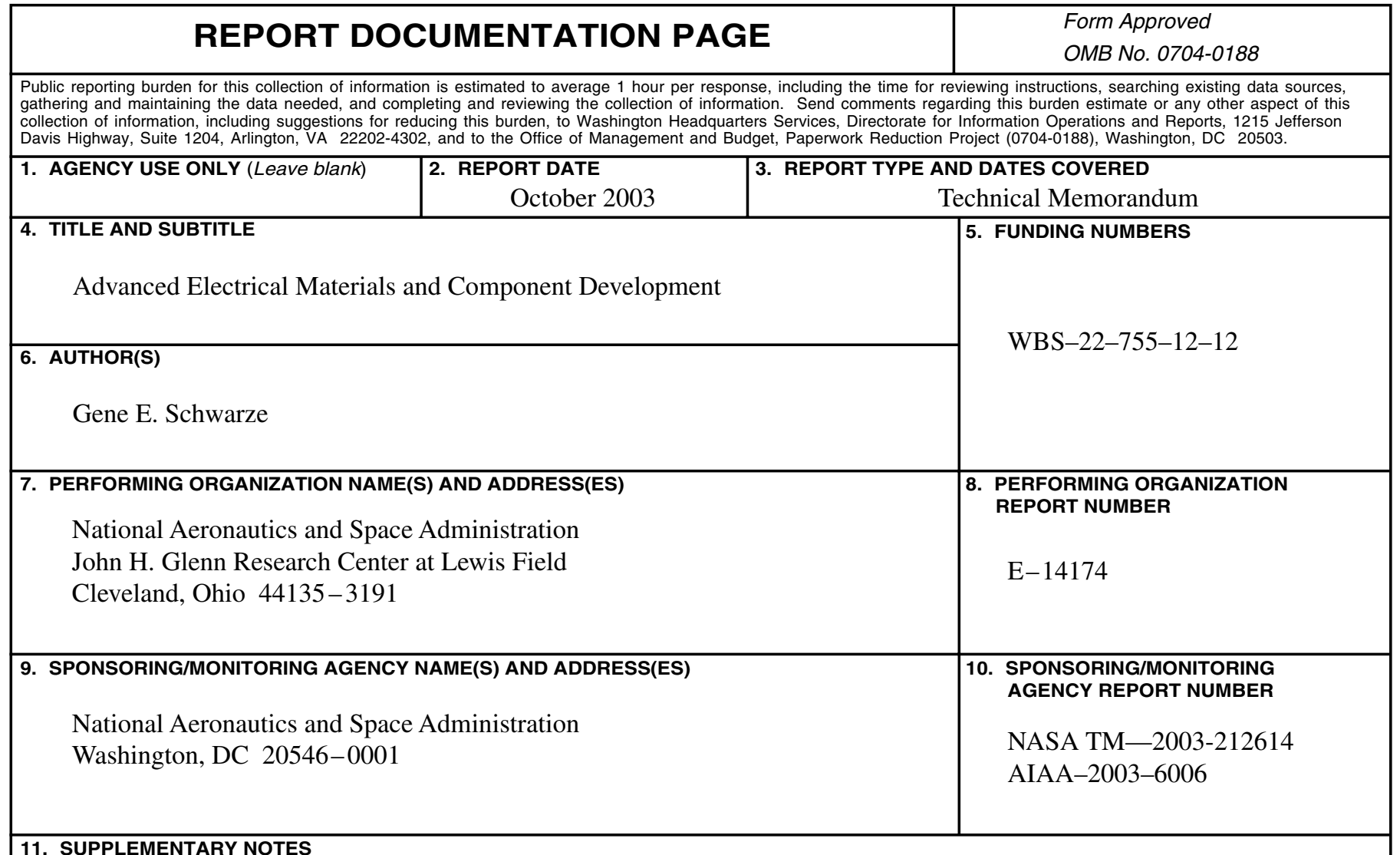

\section{SUPPLEMENTARY NOTES}

Prepared for the First International Energy Conversion Engineering Conference cosponsored by the American Institute of Aeronautics and Astronautics (AIAA), the American Society of Mechanical Engineers (ASME), and the Institute of Electrical and Electronics Engineers (IEEE), Portsmouth, Virginia, August 17-21, 2003. Responsible person,

Gene E. Schwarze, organization code 5450, 216-433-6117.

12a. DISTRIBUTION/AVAILABILITY STATEMENT

12b. DISTRIBUTION CODE

Unclassified - Unlimited

Subject Category: 33

Distribution: Nonstandard

Available electronically at http://gltrs.grc.nasa.gov

This publication is available from the NASA Center for AeroSpace Information, 301-621-0390.

13. ABSTRACT (Maximum 200 words)

The primary means to develop advanced electrical components is to develop new and improved materials for magnetic components (transformers, inductors, etc.), capacitors, and semiconductor switches and diodes. This paper will give a description and status of the internal and external research sponsored by NASA Glenn Research Center on soft magnetic materials, dielectric materials and capacitors, and high quality silicon carbide ( $\mathrm{SiC}$ ) atomically smooth substrates. The rationale for and the benefits of developing advanced electrical materials and components for the PMAD subsystem and also for the total power system will be briefly discussed.

\begin{tabular}{|c|c|c|}
\hline \multicolumn{3}{|l|}{$\begin{array}{l}\text { 14. SUBJECT TERMS } \\
\text { Electrical components; El } \\
\text { Capacitors; Silicon carbid }\end{array}$} \\
\hline $\begin{array}{l}\text { 17. SECURITY CLASSIFICATION } \\
\text { OF REPORT }\end{array}$ & $\begin{array}{l}\text { 18. SECURITY CLASSIFICATION } \\
\text { OF THIS PAGE }\end{array}$ & $\begin{array}{l}\text { 19. SECURITY CLASSIFICATION } \\
\text { OF ABSTRACT }\end{array}$ \\
\hline Unclassified & Unclassified & Unclassified \\
\hline
\end{tabular}

NSN 7540-01-280-5500

15. NUMBER OF PAGES

16

16. PRICE CODE

20. LIMITATION OF ABSTRACT

Standard Form 298 (Rev. 2-89)

Prescribed by ANSI Std. Z39-18 298-102 